\title{
High levels of global genome methylation in patients with retinoblastoma
}

\author{
HÜLYA YAZICI ${ }^{1,2}$, HUI-CHEN WU ${ }^{1}$, HULYA TIGLI ${ }^{2,3}$, ELIF Z. YILMAZ ${ }^{2,4}$, \\ REJIN KEBUDI ${ }^{5,6}$ and REGINA M. SANTELLA ${ }^{1}$
}

\author{
${ }^{1}$ Department of Environmental Health Sciences, Mailman School of Public Health of Columbia University, \\ New York, NY 10032, USA; ${ }^{2}$ Department of Basic Oncology, Division of Cancer Genetics, Oncology Institute, \\ Istanbul University, Fatih, Istanbul 34093; ${ }^{3}$ Department of Molecular Biology, Gelişim University, Avcilar, Istanbul 34315; \\ ${ }^{4}$ Faculty of Medicine, Medipol University, Beykoz, Istanbul 34810; ${ }^{5}$ Division of Pediatric Hematology-Oncology, \\ Cerrahpaşa Medical Faculty, Istanbul University, Fatih, İstanbul 34098; ${ }^{6}$ Division of Pediatric Hematology-Oncology, \\ Oncology Institute, Istanbul University, Fatih, Istanbul 34093, Turkey
}

Received April 5, 2019; Accepted September 26, 2019

DOI: $10.3892 / 01.2020 .11613$

\begin{abstract}
Retinoblastoma is a tumor of the embryonic neural retinain young children. The DNA methyltransferase 1 (DNMT1) gene has been demonstrated to be transcriptionally activated in cells lacking retinoblastoma $1(R B I)$. Thus, there is a direct interaction between $D N M T 1$ and $R B 1$ in vivo. The present study hypothesized that uncontrolled DNMT1, DNMT2 and DNMT3 expression may lead to a high level of global genome methylation causing a second hit or where both alleles are altered, in $R B 1$ and/or inactivation of other genes in retinal cells. To test this, the global genome methylation levels were analyzed in 69 patients with retinoblastoma, as well as 26 healthy siblings and 18 healthy unrelated children as the control groups. Peripheral blood and tumor tissue samples were obtained from 32 patients. The expression levels of DNMT genes were also determined in cell lines. Based on the median levels of global genome methylation in patients, higher genome-wide methylation levels in peripheral blood were associated with a 3.33-fold increased risk for retinoblastoma in patients compared with all healthy controls (95\% confidence interval, 0.98-11.35; $\mathrm{P}<0.0001)$. The level of global genome methylation and the expression of DNMT genes were increased in the WERI-RB-1 cell line, which has a mutated $R B 1$ gene, compared with a wild-type $R B 1$-expressing cell line. These results supported the hypothesis that epigenetic alterations, as well as mutations in $R B 1$, may be associated with the oncogenesis and inheritance of
\end{abstract}

Correspondence to: Professor Hülya Yazici, Department of Basic Oncology, Division of Cancer Genetics, Oncology Institute, Istanbul University, Topkapi Mah. Turgut Özal-Millet Bulvard 118, Fatih, Istanbul 34093, Turkey

E-mail: hulyayazici67@gmail.com

Key words: global genome methylation, DNA methyltransferase genes, gene expression, retinoblastoma retinoblastoma. The repression of genes that interact with $R B 1$, such as the DNMT gene family, may be important in patients with retinoblastoma with alterations in $R B 1$, and may serve a role in the treatment and regression of retinoblastoma.

\section{Introduction}

Retinoblastoma is a childhood cancer (1). The majority of the clinical phenotypes can be explained by the double mutational inactivation of the tumor suppressor gene retinoblastoma 1 ( RBI) $(2,3)$. However, additional mutations or epigenetic changes in other signaling pathways may also be involved in tumor development in retinoblastoma (4).

Previous studies have demonstrated that although abnormal epigenetic gene silencing can occur at any time during tumor progression, it most frequently occurs during the early stages of the neoplastic process, such as in the precancerous stages of tumor development $(5,6)$. Epigenetics studies have revealed that gene expression can be modified with no total structural changes in the genomic DNA by the environment alone, or epigenetic alterations may occur early in tumor development, which may lead to genetic changes (4,7-9). The importance of epigenetic abnormalities in tumor initiation and maintenance has been demonstrated in studies of genes that were identified through random screening of cancer-cell genomes $(10,11)$. Cancer cells consistently have DNA methylation on their genome. Although global DNA hypomethylation is a very common alteration in tumor tissue, also the regional methylation which is known as promoter methylation frequently occurs in the tumor cells. However, it is not known how global hypomethylation and regional promoter methylation occur together and how they affect each other, but it is known that the enzymes responsible for these conditions are DNMT enzymes and the enzymes are expressed at higher levels in tumor cells. Global hypomethylation is a highly effective mechanism in carcinogenesis as it causes the formation of aberrant gene expression, chromosomal instability, reactivation of retrotransposons, and loss of imprinting. Furthermore, promoter methylation 
is known to cause the silencing of tumor suppressor genes. It will be understood that both global hypomethylation mechanisms and promoter methylations are thought to be involved in tumor formation together or separately. Therefore, Methylation mechanisms that can be recycled can be used for disease prevention or treatment. Indeed, there are agents such as decitabine and 5-azacytidine that are capable of reversing methylation changes and are being successfully applied, particularly in the treatment of leukemia now.

In addition, the epigenetically modified DNA landscape is stable and can be transmitted from one generation to the next. Thus, the study of these epigenetic modifications is important (10).

McCabe et al and Kooi et al $(12,13)$ demonstrated that DNA methyltransferase $1(D N M T 1)$ is transcriptionally activated in cells lacking $R B I\left(R B 1^{--}\right)$, suggesting that $D N M T 1$ is under the control of retinoblastoma protein $(\mathrm{pRb})$ and retinoblastoma-associated protein (E2F) transcription factors. Overexpression of DNMT1 is associated with tumor suppressor gene hypermethylation, which contributes to tumorigenesis (14). Alterations in both alleles of $R B 1$ are involved in the development of retinoblastoma (4). Therefore, epigenetic changes in the genome of patients with retinoblastoma may stimulate or be stimulated by $R B 1$ and/or $D N M T 1$ gene alterations to generate the first and second hits or both for cancer in early life. However, Qu et al (15) have reported that DNMT proteins were not expressed in normal retinas, whereas they were frequently expressed in tumor tissue of patients with retinoblastoma. The expression levels of DNMT1 and DNMT3a proteins were increased in poorly differentiated retinoblastoma compared with well-differentiated retinoblastoma (15). Patients with tumors exhibiting upregulated expression of DNMTs appeared to have aggressive disease and poor prognosis (15). The expression level of DNMT1 was also identified to be increased in cases with invasive retinoblastoma (15). However, it is unclear whether patients with retinoblastoma carry $R B 1$ mutations. Therefore, the association between $R B I$ mutation and the level of $D N M T 1$ expression warrants further investigation. Germ line mutations in $R B 1$ account for $15-35 \%$ of patients with familial and sporadic retinoblastoma. Therefore, other genes and epigenetic alterations may be responsible and important for familial and sporadic retinoblastoma. Berdasco et al (16) demonstrated reduced methylation in the peripheral blood in patients with retinoblastoma compared with healthy controls. In addition, they identified differences in specific genes including metallothionein, cathepsin $\mathrm{Z}$ and homeobox $\mathrm{C} 4$, as well as certain microRNAs. The common $\mathrm{CpG}$ methylation changes in the tumors and peripheral blood samples of patients with retinoblastoma were different compared with changes in the blood samples of healthy controls, suggesting that retinoblastoma may exhibit a specific methylation signature worthy of further investigation (16). Previous methylation studies have investigated the methylation of gene-specific promoters, but have not searched for intergenic regions or measured the level of methylation for the entire genome (7,17-19). The level of global genome methylation in retinoblastoma is unknown; in addition, the interaction between DNMTl gene expression and $R B 1$ mutation in cell lines is unclear according to the literature.
The present study aimed to investigate the level of global genome methylation in peripheral blood samples of patients with retinoblastoma, their healthy siblings and unrelated controls to improve the understanding of the importance of global genome methylation in retinoblastoma. In addition, the levels of genome-wide methylation in tumor tissue and in the peripheral blood samples of patients with retinoblastoma were investigated to better understand whether genome-wide methylation serves a role in the oncogenesis of retinoblastoma. Finally, the association between the expression levels of DNMT genes (DNMT1, DNMT2, DNMT3a and DNMT3b), global genome methylation and $R B 1$ mutation was investigated in the commercially available WERI-RB-1 cell line, established from the tumor tissue of a patient with retinoblastoma who had a mutation in $R B 1$, and the RWPE-2 cell line with wild-type $R B 1$.

\section{Materials and methods}

Samples. The study samples comprised 145 blood and/or tumor specimens from 69 retinoblastoma cases (46 unilateral and 23 bilateral), 26 siblings matched to the cases and 18 unrelated controls. Both peripheral blood and tumor tissues were obtained from 32 patients; 30 patients, 26 unaffected siblings and 18 unrelated healthy controls provided peripheral blood samples only and 7 patients provided tumor tissue only. The study was approved by the ethics committee of the Istanbul Medical Faculty, Istanbul University (Istanbul, Turkey). All patients and their siblings were selected from individuals who were diagnosed and treated between January 1991 and December 1996 at the Oncology Institute in Istanbul University and their relatives. Fresh tumor tissue and peripheral venous blood samples of the patients were collected during surgery, transferred to the laboratory and immediately processed. Informed consent was signed prior to collecting $10 \mathrm{ml}$ peripheral blood samples from the patient and healthy controls. The lymphocytes were separated from whole blood using the Ficoll-1077 (Sigma-Aldrich; Merck KGaA) gradient centrifugation method at $700 \mathrm{x}$ g for $30 \mathrm{~min}$ at room temperature. The white blood cells were harvested using sterile pipette tips from the surface of the Ficoll solution followed by centrifugation. The lymphocytes were washed with PBS twice and centrifuged at $700 \mathrm{x} \mathrm{g}$ for $10 \mathrm{~min}$ at room temperature. Subsequently, the cell pellets were resuspended with PBS and divided into 2 cryo tubes and centrifuged at $700 \mathrm{x}$ g for $20 \mathrm{~min}$ at room temparature. The supernatant was discarded and the cell pellets were frozen at $-80^{\circ} \mathrm{C}$ immediately. Then they were stored as cell pellets in liquid nitrogen until further use.

Fresh tissues were dissected into $2-3 \mathrm{~mm}^{3}$ pieces and incubated into The RNALater solution at $4^{\circ} \mathrm{C}$ for at least $24 \mathrm{~h}$. The following day, the tissues were removed from the RNALater stabilization solution (cat. no. AM7020; Invitrogen; Thermo Fisher Scientific, Inc.) and placed in cryotubes for storage in liquid nitrogen. Unrelated healthy controls were selected from healthy children attending Istanbul Medical Faculty, Department of Pediatrics at Istanbul University, for routine health assessment, with no history of cancer in first, second and third-degree relatives and were age- and ethnicity matched with the patients. A total of $5 \mathrm{ml}$ of peripheral blood was obtained from each healthy control and also for healthy 
siblings of the patients. Family histories were obtained from the patients, and pedigrees were drawn. The mean $( \pm \mathrm{SD})$ and median ages of the patients with retinoblastoma were 18.46 \pm 15.61 and 14 months (range, 1.32-84.29 months), respectively. The mean $( \pm \mathrm{SD})$ and median ages of the siblings were 93.10 \pm 60.59 and 84.96 months (range, 12.48-204.10 months), respectively. The mean $( \pm \mathrm{SD})$ and median ages of the unrelated healthy controls were $19.96 \pm 16.16$ and 15 months (range, 2.27-92.44 months), respectively. $47 \%$ of cases, including the patients, siblings and healthy controls participated in the study, were female and $53 \%$ were male. The DNA was isolated by the phenol/chloroform (1:1) extraction method following overnight incubation with proteinase $\mathrm{K}$ at $37^{\circ} \mathrm{C}$ as described previously published article (20). The DNA concentration was measured using a Pico Green ds DNA Assay kit (Thermo Fisher Scientific, Inc.) at a wavelength of $485 / 535 \mathrm{~nm}$ in visible/UV spectrometer.

Mutation analysis of the RBI gene in patients with retinoblastoma. A total of 27 patients in the cohort were tested for the presence of small indel mutations and large genomic rearrangements (LGRs). The peripheral blood of patients with diagnosed retinoblastoma was used for sequencing for the full exons of the $R B 1$ gene by Sanger sequencing using CEQ8000 and GXL dye terminator cycle sequencing (Beckman Coulter, Inc.) systems, and LGRs were screened using multiplex ligation-dependent probe amplification (MLPA) analysis. All coding exons and adjacent intronic splice junction regions of the $R B 1$ gene were screened for mutations in the fragments between 150 and 823 bp for Sanger sequencing. The reference sequence ENST00000267163/NM_000321.2 (21) was used for the $R B 1$ gene. All DNA sequencing results were read according to the hg19 genomic sequence.

LGRs in the RBl gene were evaluated using MLPA analysis in the study cohort. MLPA analysis was performed using MRC-Holland probe set for the RB1 gene (MLPA RB1: P047; MRC-Holland) according to the manufacturer's instructions. At least one negative and three normal controls were included in each experimental batch, as well as DNA molecular weight markers. Amplified DNA was run on CEQ8000 and GXL Beckman Coulter DNA sequencer (Beckman Coulter, Inc.) for fragment analysis. Raw data of fragment analyses were analyzed and peak areas were calculated using Coffalyser analysis software $(22,23)$.

Methyl acceptance assay. Genome-wide DNA methylation was determined by the methyl acceptance assay using the protocol described by Balaghi and Wagner (24). A mixture of 100-250 ng genomic DNA, $2 \mu \mathrm{Ci} S$-adenosyl-L-(methyl ${ }^{3} \mathrm{H}$ ) methionine (SAM; GE Healthcare Life Sciences) and $1 \mathrm{X}$ enzyme buffer (New England BioLabs, Inc.) in the presence of 3 units of $S s s 1$ methylase (New England BioLabs, Inc.) were incubated at $37^{\circ} \mathrm{C}$ for $80 \mathrm{~min}$. All samples were run in duplicate and the reactions were performed in a $30 \mu \mathrm{l}$ reaction volume with stopping on ice. The enzymatically methylated DNA was isolated from the reaction mixture by filtering $15 \mu \mathrm{l}$ of the reaction solution on Whatman DE81 ion exchange filters (Whatman, Inc.) and washing three times with $5 \mathrm{ml} 0.5 \mathrm{M}$ phosphate buffer (pH 7.0) and twice with $2 \mathrm{ml} 70$ and 100\% ethanol in a sampling manifold unit (EMD Millipore). The dried filters were placed into vials containing $5 \mathrm{ml}$ scintillation liquid (Ultima Gold; Perkin Elmer, Inc.), and counted in a Packard-Tricarb 2100TR liquid scintillation analyzer (Perkin Elmer, Inc.). The mean disintegrations per minute (DPM) values were divided by the amount of DNA used for evaluating the global genome methylation levels. Duplicate incubations without the Sss 1 methylase enzyme were used as the blank control. Commercial methylated DNA (Chemicon International; Thermo Fisher Scientific, Inc. cat. no. S7821), DNA from a random lymphoblastoid cell line (requited from the sample registry of Oncology Institute, Istanbul University), whole genome amplified DNA and commercial unmethylated DNA (Chemicon International; Thermo Fisher Scientific, Inc. cat. no. S7822) were assayed with each batch to determine reaction precision, integrity and variability (data not shown).

The cost-effective and fast protocol developed by Balaghi and Wagner (24) was used for measuring the level of global genome methylation in the present study. The unmethylated CpGs that were present throughout the genome became methylated. Methylation levels were determined by measuring DNA radioactivity; high amounts of radioactive methyl groups binding to DNA in the assay suggested that the DNA exhibited low initial methylation levels, whereas low amounts of methyl binding to the DNA indicated that the DNA was highly methylated initially.

Expression levels of DNMT genes in retinoblastoma and normal cell lines. Expression levels of the DNMT genes (DNMT1, DNMT2, DNMT3 $a$ and DNMT3b) were investigated in the commercially available WERI-RB-1 cell line, which was established from the tumor tissue of a retinoblastoma patient with an $R B 1$ mutation, and a prostatic epithelial cell line RWPE-2 (both American Type Culture Collection; ATCC), which carried an intact $R B 1$ gene. The extent to which $R B 1$ gene mutations affect the expression of DNMT genes in different cell lines was investigated in these experiments, and the experimental design has been based on the genetic status of the cells. Therefore, two different cell lines with either $R B 1$ gene mutations or the wild-type gene were selected. The only cell line from ATCC known to have the $R B I$ gene intact is the RWPE-2 cell line. The two cell lines were cultured in appropriate media (RPMI-1640 media for WERI-RB1, Keratinocyte Serum Free Medium for RWPE-2; Invitrogen; Thermo Fisher Scientific, Inc.) according to the ATCC protocols and were harvested to extract RNA and DNA using a commercial DNA/RNA isolation kit and protocols given by the firm (AllPrep DNA/RNA mini kit; Qiagen, Inc.). RNA was converted to cDNA using Invitrogen Superscript III kit with random primers and oligo(dT)20, and reverse transcriptase enzyme (SuperScript IV) at $50^{\circ} \mathrm{C}$ for $30 \mathrm{~min}$ (Invitrogen; Thermo Fisher Scientific, Inc.) in a thermal cycler (Biorad T100; Bio-Rad Laboratories Inc.). Expression levels of DNMT genes were measured using SyberGreen (Thermo Fisher Scientific, Inc.) by quantitative PCR using ABI 7500 (Applied Biosystems; Thermo Fisher Scientific, Inc.) and normalized to $G A P D H$ expression levels using primers described by Saito et al (25): DNMT1 forward, 5'-CCCCTGAGCCCTACC GAAT-3' and reverse, 5'-CTCGCTGGAGTGGACTTGTG-3', 142 bp; DNMT2 forward, 5'-AAGCTGTAAGCCAGCCCA TATA-3' and reverse, 5'-TCAGCAGTGAACAGAACCTAC 
ATG-3', 148 bp; DNMT3a forward, 5'-TTCTACCGCCTC CTGCATGAT-3' and reverse, 5'-GCGAGATGTCCCTCT TGTCACTA-3', 113 bp; DNMT3b forward, 5'-GAATTACTC ACGCCCCAAGGA-3' and reverse, 5'-ACCGTGAGATGT CCCTCTTGTC-3', $101 \mathrm{bp}$; GAPDH forward, 5'-GAAGGT GAAGGTCGGAGTC-3' and reverse, 5'-GAAGATGGTGAT GGGATTTC-3', 226 bp. Gene expression was calculated using the following formula: $2^{-\Delta \Delta \mathrm{Cq}}(26)$. According to this method, the results were determined based on the $\mathrm{Cq}$ value, which was the first significant increase in the PCR product amount. The $\Delta \mathrm{Cq}$ value, which determined the difference between the target gene and the reference gene were calculated separately for both the mutated cell line and the cell line containing the intact $R B 1$ gene. The magnitude of increase or decrease in DNMTs gene expression of both cell lines in reference to $G A D P H$ gene expression was determined using the $2^{-\triangle \Delta C q}$ method (26).

Statistical analysis. The levels of global methylation data are presented as median \pm interquartile range (IQR). The Mann-Whitney U test was used to compare the differences in median global methylation levels between tumor tissues and peripheral blood samples of the patients and between cases and controls. In addition, the Spearman's Rank-Order correlations test was used to determine the correlation between the global methylation level in peripheral blood and tissue. Sexand age-adjusted logistic regression was used to calculate the odds ratio; the cut-off value was the median methylation level in peripheral blood among patients. A Bonferroni-corrected $\mathrm{P}<0.025$ was considered to indicate a statistically significant difference. All analyses were performed with SAS software 9.4 (SAS Institute).

\section{Results}

Levels of global genome methylation in peripheral blood samples in patients with retinoblastoma and healthy control. Global genome methylation levels were significantly higher in the peripheral blood $(\mathrm{P}<0.0001)$ and tumor tissues $(\mathrm{P}<0.044)$ of patients with retinoblastoma compared with those in the peripheral blood of the healthy controls (Table I). In the subset of patients $(n=26)$ whose healthy siblings provided peripheral blood, the global genome methylation levels in the peripheral blood of patients were higher compared with their healthy siblings ( $\mathrm{P}<0.02$; Table II). Global genome methylation levels in the peripheral blood were significantly higher in patients with bilateral $(\mathrm{P}<0.0084)$ and unilateral retinoblastoma $(\mathrm{P}<0.0007)$ compared with all healthy controls (Table III). The levels of global genome methylation in the peripheral blood of patients with retinoblastoma were 2.6-fold higher compared with the levels in the peripheral blood of siblings and unrelated healthy controls. Based on the median levels of global genome methylation in patients with retinoblastoma, high global genome methylation levels in peripheral blood samples were identified to be associated with a 3.33-fold increased risk for retinoblastoma compared with all healthy controls $(95 \% \mathrm{CI}$, 0.98-11.35; $\mathrm{P}<0.0001$; Table IV).

Levels of global genome methylation in tumor tissue and peripheral blood of patients with retinoblastoma. The levels of global genome methylation were 1.5 -fold higher in the DNA isolated from the tumor tissue compared with that from the peripheral blood in patients with retinoblastoma. There was a correlation between global genome methylation levels in pairs of tumor tissues and peripheral blood samples from patients with retinoblastoma $(\mathrm{P}<0.046 ; \mathrm{R}=0.366$; Table $\mathrm{I})$. No significant association was observed between global genome methylation levels and family history of other types of cancer $(\mathrm{P}<0.27)$.

Levels of DNMT1, DNMT2, DNMT3a and DNMT3b gene expression and global genome methylation in the WERI-RB-1 and RWPE-2 cell lines. No appropriate RNA samples were available at Istanbul University-Oncology institute biospecimen bank to measure the expression levels of DNMTs in the patients and healthy controls. However, the expression levels of $D N M T$ genes that are responsible for methylation were investigated in vitro as higher levels of global genome methylation levels were demonstrated in the peripheral blood samples of the patients in this study. The expression levels of DNMT1, $D N M T 2, D N M T 3 a$ and $D N M T 3 b$ were investigated in a human retinoblastoma tumor cell line (WERI-RB-1), which is $R B 1^{-/ \text {, }}$, and a cell line that has an intact $R B 1$ (RWPE-2). The expression levels of all DNMT genes were higher in WERI-RB-1 cells compared with those in RWPE-2 cells. The expression levels were 6.2-fold higher for DNMT1, 90.3-fold higher for $D N M T 2,57.2$-fold higher for DNMT3a and 5.8-fold higher for $D N M T 3 b$ in the WERI-RB-1 cell line compared with RWPE-2 cells. The values of DPM $/ \mu \mathrm{g}$ were 75.598 and 432.951 in the WERI-RB-1 cell line and the RWPE-2 cell line, respectively. The level of global genome methylation in the WERI-RB-1 cell line with a $R B 1$ mutation was 5.72-fold higher compared with the levels in the RWPE- 2 cell line with wild-type $R B 1$ gene. No significance differences were observed in the values of DPM $/ \mu \mathrm{g}$ between the WERI-RB-1 cell line and tumor tissues from patients with retinoblastoma, as well as between the RWPE-2 cell line and the peripheral blood of controls $(\mathrm{P}>0.05)$.

Mutation frequency of $R B 1$ gene in patients with retinoblastoma. A subset of 27 patients (39\% of the patient cohort) in the study was screened for $R B 1$ mutations. The total mutation frequency in patients with retinoblastoma was $37 \%$ (10/27); among patients with mutations, the frequency of LGRs was $30 \%(3 / 10)$, whereas the frequency of indels was $70 \%(7 / 10)$. The level of global genome methylation ranged between 131.859 and $270.647 \mathrm{DPM} / \mu \mathrm{g}$ in patients carrying $R B 1$ mutations. The mean and median DPM $/ \mu \mathrm{g}$ in patients with $R B 1$ mutations were 123.732 and 138.356 , respectively. These values in patients with $R B 1$ mutations were lower compared with the overall median and mean DPM/ $\mu$ g levels of global genome methylation in the peripheral blood of 69 patients with retinoblastoma.

\section{Discussion}

Retinoblastoma, which is a prototype of hereditary cancer, is the most common intraocular tumor in children (27). The incidence of retinoblastoma is $\sim 11$ new cases per million individuals, particularly for early age (under 5-years of age) 
Table I. Distribution of global genome methylation levels in the tumor tissues $(n=39)$ and peripheral blood ( $n=69)$ of patients with retinoblastoma and the peripheral blood of all healthy controls $(n=44)$, including unaffected healthy siblings and unrelated healthy controls.

\begin{tabular}{lccc}
\hline Variable & $\begin{array}{c}\text { Tumor tissues } \\
\text { of patients, } \mathrm{n}\end{array}$ & $\begin{array}{c}\text { Peripheral blood } \\
\text { of patients, } \mathrm{n}\end{array}$ & $\begin{array}{c}\text { Peripheral blood } \\
\text { of healthy controls, } \mathrm{n}\end{array}$ \\
\hline Mean DPM/ $\mu \mathrm{g}$ & 99,197 & 14,9170 & 38,9569 \\
Median DPM/ $\mu \mathrm{g}$ & 19,164 & 13,0726 & 34,6699 \\
Q3-Q1 & 13,8273 & 23,4096 & 53,5779 \\
P-value & $0.044^{\mathrm{a}}$ & $<0.0001^{\mathrm{a}}$ & -
\end{tabular}

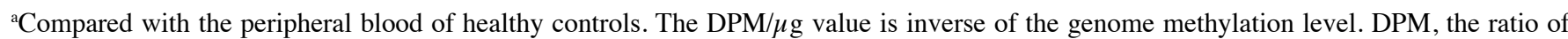
radioactivity counts per min inside the sample compositions in scintillation counters; Q, quartile.

Table II. Global genome methylation levels in peripheral blood DNA of patients with retinoblastoma $(n=26)$ and their unaffected healthy siblings $(n=26)$.

\begin{tabular}{lcc}
\hline Variable & Patients, $\mathrm{n}$ & Siblings, $\mathrm{n}$ \\
\hline Mean DPM/ $\mu \mathrm{g}$ & 186,536 & 329,189 \\
Median DPM/ $\mu \mathrm{g}$ & 185,859 & 323,112 \\
Q3-Q1 & 240,984 & 472,568 \\
P-value & 0.02 & - \\
\hline
\end{tabular}

The DPM $/ \mu$ g value is inverse of the genome methylation level. DPM, the ratio of radioactivity counts per min inside the sample compositions in scintillation counters; Q, quartile.

in America and Europe (28). The disease may be fatal if left untreated. Therefore, understanding the genetic risks involves can assist with early diagnosis of the disease and also treatment, which can save both the vision and life of the patients. Most clinical phenotypes can be explained by double mutational inactivation of RBI (29). However, additional mutations or alterations such as epigenetic changes may be involved in the etiology of retinoblastoma $(30,31)$. In addition, a detailed analysis of the association between genotype and phenotype suggests that hereditary retinoblastoma exhibits features of a complex trait (31). Although loss of heterozygosity and mutations in $R B I$ are frequently observed in tumors of multiple tissue types and are typically considered to serve an oncogenic role (32), the precise mechanism underlying tumorigenesis has not been fully elucidated. Inactivation of $R B 1$ has been associated with increased tumor susceptibility in several model systems $(33,34)$. Abnormal $\mathrm{pRb}$ leads to deregulation of E2F target genes, such as cyclin $\mathrm{E}$, thymidine kinase and DNA polymerase $\alpha$, which control the cell cycle (35-38). In addition, McCabe et al and Kooi et al $(12,13)$ demonstrated that the aberrant regulation of DNMT1 in $R B 1^{-/-}$prostate epithelium was associated with increased DNA hypermethylation. Additionally, the DNMT1 promoter has been demonstrated to be regulated by the $\mathrm{pRb} / \mathrm{E} 2 \mathrm{~F}$ pathway in murine and human cell lines of an epithelial or fibroblast origin $(12,13)$. In the absence of $\mathrm{pRb}$, DNMT1 transcripts exhibited aberrant cell cycle regulation (12). Upregulation of DNA methyltransferases has been reported in multiple types of tumor, including breast, colon, lung and prostate cancer, as well as retinoblastoma (15). Increased expression of DNMTs in tumors was significantly correlated with increased methylation of $\mathrm{CpG}$ islands within the promoters of tumor suppressor genes, which suggested a functional role for DNMT upregulation in cancer (39-43). In addition, several studies have demonstrated that the expression levels of DNMTs are progressively elevated in samples representing colon cancer progression with increasing expression from normal tissue in healthy subjects to polyps and finally to carcinoma (41-44). It was reported cases of retinoblastoma in which one allele of the $R B I$ was mutated, whereas the other was apparently normal in sequence, but not expressed in tumor cells; treatment of the cells with the demethylating drug 5-azacytidine induced the reactivation of the silent allele. This was developed into a hypothesis that tumor suppressor genes were inactivated by epigenetic events, rather than by mutation, in certain cases $(14,45)$. Greger et al (46) demonstrated that hypermethylation of $R B 1$ occurred in $13 \%$ of sporadic unilateral tumors and may reduce gene activity. Quiñonez-Silva et al (47) reported that the inactivation of the second allele in $R B 1$ occurred via methylation. Additionally, Livide et al (17) identified epigenetic alterations in tumor protein p53, cadherin 13, GATA-binding protein 5, checkpoint with forkhead and ring finger domains and immunoglobulin superfamily member 4. Another study reported that Ras association domain family member 1 was methylated in $82 \%$ of patients with retinoblastoma (48). Mol et al (49) suggested that retinoblastoma tumors may exhibit highly variable levels of genome stability, even if genetic alterations such as loss of heterozygosity ( $\mathrm{LOH})$, local amplification or copy number variation were rare in patients with retinoblastoma. Zhang et al (4) performed whole genome sequencing of four primary retinoblastoma tumors and matched normal tissues and revealed that the average number of structural alterations was 10 per case; their data on genomic instability was insufficient to explain retinoblastoma development, which further indicated that epigenetic mechanisms may contribute to retinoblastoma tumorigenesis in addition to structural events. In addition, their results revealed that without epigenetic alterations and genomic instability, the inactivation of both $R B 1$ alleles is insufficient to result in retinoblastoma (33). A study conducted by Dimaras et al (50) explored the molecular 
Table III. Distribution of global genome methylation levels in patients with unilateral $(\mathrm{n}=46)$ and bilateral $(\mathrm{n}=23)$ retinoblastoma and all healthy controls $(n=44)$, including healthy siblings and unrelated healthy controls.

\begin{tabular}{lccc}
\hline Variable & Patients with bilateral RB, & Patients with unilateral RB, $\mathrm{n}$ & Healthy controls, $\mathrm{n}$ \\
\hline Mean DPM/ $\mu \mathrm{g}$ & 112,938 & 159,142 & 389,569 \\
Median DPM/ $\mu \mathrm{g}$ & 19,988 & 155,517 & 346,699 \\
Q3-Q1 & 125,534 & 233,443 & 535,779 \\
P-value $^{\text {a }}$ & 0.0084 & 0.0007 & - \\
\hline
\end{tabular}

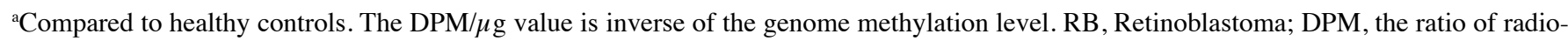
activity counts per min inside the sample compositions in scintillation counters; Q, quartile.

Table IV. Distribution of global genome methylation levels according to the median value in the peripheral blood of patients $(n=69)$ with retinoblastoma and all healthy controls $(n=44)$.

\begin{tabular}{lccc}
\hline Variable & Patients, $\mathrm{n}$ & Healthy controls, $\mathrm{n}$ & OR (95\% CI) \\
\hline Low methylation level, DPM $/ \mu \mathrm{g} \geq 346,699$ & 31 & 31 & 1 \\
High methylation level, DPM $/ \mu \mathrm{g}<346,699$ & 38 & 13 & $3.33(0.98-11.35)$ \\
\hline
\end{tabular}

DPM, the ratio of radioactivity counts per min inside the sample compositions in scintillation counters. High DPM/ $/ \mathrm{g}$ value is shown the inverse of methylation levels in the genome.

definition of retinoma; the results demonstrated that the expression levels of oncogenes and tumor suppressor genes in retinoma were different compared with those in retinoblastoma. These results may suggest that methylation is one of the molecular switches that serve a role in genomic instability in the progression of retinoma to retinoblastoma. Since tumor tissues of patients with retinoblastoma have a biallelic alteration in the $R B I$ gene, extra alterations in the second allele of $R B 1$ gene are required for retinoblastoma progression (16). DNMT1 activation is controlled by $\mathrm{pRb}$ and $\mathrm{E} 2 \mathrm{~F}$ transcription factors. McCabe et al (12) and Kooi et al (13) revealed that DNMT1 was highly expressed in the cells lacking the RB1 gene. However, the altered DNMT1 expression can change the methylation status of proto-oncogenes, tumor suppressor genes and other intergenic regions in the genome for the progression of retinoblastoma (51-53). In agreement with studies that emphasized the importance of methylation, the results of the present study suggested that the level of global genome methylation may be important for the oncogenesis and inheritance of retinoblastoma. Berdasco et al (16) have suggested that retinoblastoma may have a specific methylation signature, which needs to be further investigated.

In the present study, the level of global genome methylation was measured in the tumor tissues of patients with retinoblastoma and peripheral blood samples of patients with retinoblastoma, their unaffected siblings and unrelated healthy controls to evaluate whether global genome methylation may be a marker for the inheritance of familial retinoblastoma. The levels of global genome methylation were 1.5-fold higher in DNA derived from the tumor tissue compared with that derived from the peripheral blood in patients with retinoblastoma.
The germline inactivation of $R B 1$ gene has been found in 25-35\% of retinoblastoma (54). Expression of DNMT1, which is responsible for global genome methylation in cells, is elevated by the loss of RBI $(12,15)$. The present study demonstrated that the methylation levels in peripheral blood samples of patients with retinoblastoma were 2.6-fold elevated compared with those in the peripheral blood of their siblings and unrelated healthy controls. The higher global genome methylation levels in peripheral blood samples were associated with a 3.33-fold increased risk for retinoblastoma $(\mathrm{P}<0.0001)$. These results suggested that global genome methylation level was higher in patients with retinoblastoma. There was a correlation between the global genome methylation levels in the paired tumor tissues and peripheral blood samples of the patients. The level of global genome methylation in peripheral blood may be used as an alternative biomarker for the inheritance of retinoblastoma following confirmation of these results in a larger study.

The correlations between the expression levels of DNMT1,DNMT2, DNMT3 $a$ and DNMT3b and the levels of global genome methylation could not be in patients in the present study as the RNAs from the tissues or peripheral blood samples of patients with retinoblastoma were unavailable. Instead, the expression levels of DNMT genes and the levels of global genome methylation were investigated in a commercial human retinoblastoma tumor cell line which has defective $R B 1$ and a cell line which has antact $R B 1$. High levels of expression of all four DNMT genes were identified in the cell line with mutant $R B I$ compared with the cell line with intact $R B 1$. In addition, the mean and median values of global genome methylation levels in 27 patients with $R B 1$ mutations were lower compared with those in all patients with retinoblastoma. These results suggested that 
the levels of $D N M T$ expression were affected by alterations in $R B 1$, which in turn affected the global genome methylation status.

Based on these results, high levels of genome-wide methylation may result in inactivation of other genes and regions in the genome and lead to $\mathrm{LOH}$ in the second allele of $R B 1$ or other genes in familial and sporadic cases of retinoblastoma. This may explain why retinoblastoma develops rapidly at an early age. In addition, epigenetic alterations in addition to mutations in $R B 1$ are important in the development and inheritance of retinoblastoma (7). The repression of genes that interact with $R B 1$, such as the $D N M T$ gene family, which is involved in de novo methylation, may be important for inactivation of the $R B 1$ gene and development of retinoblastoma disease in patients with familial and sporadic retinoblastoma and may serve a role in the treatment of retinoblastoma and tumor regression. In agreement with previous retinoblastoma methylation studies, the results of the present study emphasized that global genome hypermethylation may serve a functional role in molecular switching and may be responsible for genomic instability during retinoblastoma oncogenesis, which occurs at an early age and progresses rapidly.

In conclusion, the results of the present study demonstrated that retinoblastoma exhibited a unique methylation profile in the entire genome of the peripheral blood in patients with retinoblastoma, highlighted the importance of epigenetics and demonstrated an association between global genome methylation and the expression of DNMT genes, which have not previously been associated with the risk of retinoblastoma and familial retinoblastoma. Therefore, the correlations between RB1 mutation and DNMT gene expression and between $D N M T$ expression and global methylation levels have been shown for the cell lines investigated in the present study. The results are suggested that there are interactions between $R B 1$, DNMTs genes and global methylation in the genome for developing retinoblastoma. The present study had several limitations; the expression levels of DNMT genes could not be measured in due to of the absence of RNA materials in Istanbul University-Oncology Institute, and the $R B 1$ mutation screening could only be performed in 27 of the 69 patients. However, the results demonstrated that global genome methylation may be involved in retinoblastoma oncogenesis, and that this may be determined in the peripheral blood samples of patients with familial retinoblastoma.

Understanding the molecular events that initiate and maintain epigenetic gene silencing may lead to the development of clinical strategies for cancer prevention and therapies that reverse the silencing process. The results of the present study present a different perspective of the oncogenesis and inheritance of retinoblastoma and should be further examined in a larger sample of patients with retinoblastoma and with regressed tumors.

\section{Acknowledgements}

The authors would like to thank Dr Guillermo Chantada (Hospital Sant Joan de Déu, Barcelona, Spain) and Dr Juan P. Garrahan (Pediatric Hospital, Buenos Aires, Argentina) for reviewing the draft of the manuscript; Dr Yoon Hee Cho (Department of Environmental Health Sciences, Mailman School of Public Health of Columbia University, New York, NY,
USA) for assistance with the cell line study; and Dr Jennifer Zipprich (Department of Environmental Health Sciences, Mailman School of Public Health of Columbia University, New York, NY, USA) for critical reading of the manuscript.

\section{Funding}

This study was funded by Istanbul University with project number BAY:TAS-2017-23070, Istanbul University-Cerrahpaşa with project number BYP-2019-32977 and the AVON-AACR foundation with grant number 2005-2007.

\section{Availability of data and materials}

The datasets used and/or analyzed during the current study are available from the corresponding author on reasonable request.

\section{Authors' contributions}

RK recruited and referred patients to the study and helped with their follow-up. HY performed the experiments and wrote the manuscript. HCW performed statistical analysis. All the radioactive material required for the experimental processes of the study was provided by RMS. RMS also contributed towards the interpretation of data, writing of the manuscript and language editing of the manuscript. RK edited the manuscript and contributed to criticism and increased the scientific value of writing. HT and EZY recruited healthy cases to the study, collected the data, drew pedigrees, filled in demographic information forms and prepared all documents to transfer the samples to the laboratory in the USA from Turkey and also performed all DNA extractions of specimens in the study. All authors read and approved the final manuscript.

\section{Ethics approval and consent to participate}

All procedures performed in studies involving human participants were in accordance with the ethical standards of the institutional and/or national research committee and with the 1964 Helsinki declaration and its later amendments or comparable ethical standards. The study was approved by the Ethics Committee of Istanbul Medical Faculty in Istanbul University (approval no. 247815). Written informed consent was provided by the parents/guardians of the participants included in the study.

\section{Patient consent for publication}

Not applicable.

\section{Competing interests}

The authors declare that they have no competing interests.

\section{References}

1. Parkin DM, Stiller CA, Draper GJ and Bieber CA: The international incidence of childhood cancer. Int J Cancer 42: 511-520, 1988.

2. Knudson AG Jr: Mutation and cancer: Statistical study of retinoblastoma. Proc Natl Acad Sci USA 68: 820-823, 1971. 
3. Friend SH, Bernards R, Rogelj S, Weinberg RA, Rapaport JM, Albert DM and Dryja TP: A human DNA segment with properties of the gene that predisposes to retinoblastoma and osteosarcoma. Nature 323: 643-646, 1986.

4. Zhang J, Benavente CA, McEvoy J, Flores-Otero J, Ding L, Chen X, Ulyanov A, Wu G, Wilson M, Wang J, et al: A novel retinoblastoma therapy from genomic and epigenetic analyses. Nature 481: 329-334, 2012.

5. Feinberg AP and Tycko B: The history of cancer epigenetics. Nat Rev Cancer 4: 143-153, 2004

6. Yamada Y, Jackson-Grusby L, Linhart H, Meissner A, Eden A, Lin $\mathrm{H}$ and Jaenisch R: Opposing effects of DNA hypomethylation on intestinal and liver carcinogenesis. Proc Natl Acad Sci USA 102: 13580-13585, 2005.

7. Singh U, Malik MA, Goswami S, Shukla S and Kaur J: Epigenetic regulation of human retinoblastoma. Tumour Biol 37: 14427-14441, 2016.

8. Benavente CA, McEvoy JD, Finkelstein D, Wei L, Kang G, Wang YD, Neale G, Ragsdale S, Valentine V, Bahrami A, et al: Cross-species genomic and epigenomic landscape of retinoblastoma. Oncotarget 4: 844-859, 2013.

9. Li W, Liu J and Galvin JA: Epigenetics and common ophthalmic diseases. Yale J Biol Med 89: 597-600, 2016.

10. Franklin TB and Mansuy IM: Epigenetic inheritance in mammals: Evidence for the impact of adverse environmental effects. Neurobiol Dis 39: 61-65, 2010.

11. Sharma S, Kelly TK and Jones PA: Epigenetics in cancer. Carcinogenesis 31: 27-36, 2010.

12. McCabe MT, Davis JN and Day ML: Regulation of DNA methyltransferase 1 by the $\mathrm{pRb} / \mathrm{E} 2 \mathrm{~F} 1$ pathway. Cancer Res 65 : 3624-3632, 2005.

13. Kooi IE, van Mil SE, MacPherson D, Mol BM, Moll AC, Meijers-Heijboer H, Kaspers GJ, Cloos J, Te Riele H and Dorsman JC: Genomic landscape of retinoblastoma in $\mathrm{Rb}^{-/} \mathrm{p} 130^{-/}$ mice resembles human retinoblastoma. Genes Chromosomes Cancer 56: 231-242, 2017.

14. Greger V, Passarge E, Höpping W, Messmer E and Horsthemke B Epigenetic changes may contribute to the formation and spontaneous regression of retinoblastoma. Hum Genet 83: 155-158, 1989.

15. Qu Y, Mu G, Wu Y, Dai X, Zhou F, Xu X, Wang Y and Wei F: Overexpression of DNA methyltransferases 1, 3a, and 3b significantly correlates with retinoblastoma tumorigenesis. Am J Clin Pathol 134: 826-834, 2010

16. Berdasco $\mathrm{M}$, Gómez $\mathrm{A}$, Rubio $\mathrm{MJ}$, Català-Mora J, Zanón-Moreno V, Lopez M, Hernández C, Yoshida S, Nakama T, Ishikawa $\mathrm{K}$, et al: DNA methylomes reveal biological networks involved in human eye development, functions and associated disorders. Sci Rep 7: 11762, 2017.

17. Livide G, Epistolato MC, Amenduni M, Disciglio V, Marozza A, Mencarelli MA, Toti P, Lazzi S, Hadjistilianou T, De Francesco S, et al: Epigenetic and copy number variation analysis in retinoblastoma by MS-MLPA. Pathol Oncol Res 18: 703-712, 2012

18. Stirzaker C, Millar DS, Paul CL, Warnecke PM, Harrison J, Vincent PC, Frommer M and Clark SJ: Extensive DNA methylation spanning the $\mathrm{Rb}$ promoter in retinoblastoma tumors. Cancer Res 57: 2229-2237, 1997.

19. Tosi GM, Trimarchi C, Macaluso M, La Sala D, Ciccodicola A, Lazzi S, Massaro-Giordano M, Caporossi A, Giordano A and Cinti C: Genetic and epigenetic alterations of RB2/p130 tumor suppressor gene in human sporadic retinoblastoma: Implications for pathogenesis and therapeutic approach. Oncogene 24 5827-5836, 2005.

20. Yazici H, Dolapcioglu K, Buyru F and Dalay N: Utility of c-erbB-2 expression in tissue and sera of ovarian cancer patients. Cancer Invest 18: 110-114, 2000.

21. Atanesyan L, Steenkamer MJ, Horstman A, Moelans CB, Schouten JP and Savola SP: Optimal Fixation Conditions and DNA Extraction Methods for MLPA Analysis on FFPE TissueDerived DNA. Am J Clin Pathol. 147: 60-68, 2017

22. Coffa J, van de Wiel MA, Diosdado B, Carvalho B, Schouten J, and Meijer GA: MLPAnalyzer: data analysis tool for reliable automated normalization of MLPA fragment data. Cell Oncol 30 323-335, 2008

23. van Eijk R, Eilers PH, Natte R, Cleton-Jansen AM, Morreau H, van Wezel T and Oosting J: MLPAinter for MLPA interpretation: an integrated approach for the analysis, visualisation and data management of Multiplex Ligation-dependent Probe Amplification. BMC Bioinformatics 11:67-73, 2010.
24. Balaghi $\mathrm{M}$ and Wagner C: DNA methylation in folate deficiency: Use of CpG methylase. Biochem Biophys Res Commun 193: 1184-1190, 1993.

25. Saito Y, Kanai Y, Sakamoto M, Saito H, Ishii H and Hirohashi S: Expression of mRNA for DNA methyltransferases and methyl-CpG-binding proteins and DNA methylation status on $\mathrm{CpG}$ islands and pericentromeric satellite regions during human hepatocarcinogenesis. Hepatology 33: 561-568, 2001.

26. Livak KJ and Schmittgen TD: Analysis of relative gene expression data using real-time quantitative PCR and the 2(-Delta Delta C(T)) method. Methods 25: 402-408, 2001.

27. Soliman SE, Racher H, Zhang C, MacDonald H and Gallie BL: Genetics and molecular diagnostics in retinoblastoma-an update. Asia Pac J Ophthalmol (Phila) 6: 197-207, 2017.

28. Ortiz MV and Dunkel IJ: Retinoblastoma. J Child Neurol 31: 227-236, 2016

29. Cavenee WK, Dryja TP, Phillips RA, Benedict WF, Godbout R, Gallie BL, Murphree AL, Strong LC and White RL: Expression of recessive alleles by chromosomal mechanisms in retinoblastoma. Nature 305: 779-784, 1983

30. Gallie BL, Campbell C, Devlin H, Duckett A and Squire JA: Developmental basis of retinal-specific induction of cancer by RB mutation. Cancer Res 59 (Suppl 7): 1731S-1735S, 1999.

31. Lohmann DR and Gallie BL: Retinoblastoma: Revisiting the model prototype of inherited cancer. Am J Med Genet C Semin Med Genet 129C: 23-28, 2004.

32. Costa-Pinheiro P, Montezuma D, Henrique R and Jeronimo C: Diagnostic and prognostic epigenetic biomarkers in cancer. Epigenomics 7: 1003-1015, 2015

33. Jacks T, Fazeli A, Schmitt EM, Bronson RT, Goodell MA and Weinberg RA: Effects of an Rb mutation in the mouse. Nature 359: 295-300, 1992

34. Wang Y, Hayward SW, Donjacour AA, Young P, Jacks T, Sage J, Dahiya R, Cardiff RD, Day ML and bCunha GR: Sex hormone-induced carcinogenesis in $\mathrm{Rb}$-deficient prostate tissue. Cancer Res 60: 6008-6017, 2000.

35. Hurford RK Jr, Cobrinik D, Lee MH and Dyson N: pRB and p107/p130 are required for the regulated expression of different sets of E2F responsive genes. Genes Dev 11: 1447-1463, 1997.

36. Dannenberg JH, van Rossum A, Schuijff L and te Riele $H$ Ablation of the retinoblastoma gene family deregulates $\mathrm{G}(1)$ control causing immortalization and increased cell turnover under growth-restricting conditions. Genes Dev 14: 3051-3064, 2000.

37. Sage J, Mulligan GJ, Attardi LD, Attardi LD, Miller A, Chen S, Williams B, Theodorou E and Jacks T: Targeted disruption of the three $\mathrm{Rb}$-related genes leads to loss of $\mathrm{G}(1)$ control and immortalization. Genes Dev 14: 3037-3050, 2000.

38. McCabe MT, Azih OJ and Day ML: pRb-Independent growth arrest and transcriptional regulation of E2F target genes. Neoplasia 7: 141-151,2005.

39. Belinsky SA, Nikula KJ, Baylin SB and Issa JP: Increased cytosine DNA-methyltransferase activity is target-cell-specific and an early event in lung cancer. Proc Natl Acad Sci USA 93: 4045-4050, 1996.

40. Girault I, Tozlu S, Lidereau R and Bieche I: Expression analysis of DNA methyltransferases $1,3 \mathrm{~A}$, and 3B in sporadic breast carcinomas. Clin Cancer Res 9: 4415-4422, 2003.

41. el-Deiry WS, Nelkin BD, Celano P, Yen RW, Falco JP, Hamilton SR and Baylin SB: High expression of the DNA methyltransferase gene characterizes human neoplastic cells and progression stages of colon cancer. Proc Natl Acad Sci USA 88: 3470-3474, 1991.

42. Patra SK, Patra A, Zhao H and Dahiya R: DNA methyltransferase and demethylase in human prostate cancer. Mol Carcinog 33: 163-171, 2002.

43. Etoh T, Kanai Y, Ushijima S, Nakagawa T, Nakanishi Y, Sasako M, Kitano S and Hirohashi S: Increased DNA methyltransferase 1 (DNMT1) protein expression correlates significantly with poorer tumor differentiation and frequent DNA hypermethylation of multiple $\mathrm{CpG}$ islands in gastric cancers. Am J Pathol 164: 689-699, 2004.

44. Issa JP, Vertino PM, Wu J, Sazawal S, Celano P, Nelkin BD, Hamilton SR and Baylin SB: Increased cytosine DNA-methyltransferase activity during colon cancer progression. J Natl Cancer Inst 85: 1235-1240, 1993.

45. Herman JG and Baylin SB: Gene silencing in cancer in association with promoter hypermethylation. N Engl J Med 349: 2042-2054, 2003.

46. Greger V, Debus N, Lohmann D, Hopping W, Passarge E and Horsthemke B: Frequency and parental origin of hypermethylated RB1 alleles in retinoblastoma. Hum Genet 94: 491-496, 1994. 
47. Quiñonez-Silva G, Dávalos-Salas M, Recillas-Targa F, Ostrosky-Wegman P, Aranda DA and Benitez-Bribiesca L: 'Monoallelic germline methylation and sequence variant in the promoter of the RB1 gene: A possible constitutive epimutation in hereditary retinoblastoma'. Clin Epigenetics 8: 1, 2016.

48. Choy KW, Lee TC, Cheung KF, Fan DS, Lo KW, Beaverson KL, Abramson DH, Lam DS, Yu CB and Pang CP: Clinical implications of promoter hypermethylation in RASSF1A and MGMT in retinoblastoma. Neoplasia 7: 200-206, 2005.

49. Mol BM, Massink MP, van der Hout AH, Dommering CJ Zaman JM, Bosscha MI, Kors WA, Meijers-Heijboer HE, Kaspers GJ, Riele HT, et al: High resolution SNP array profiling identifies variability in retinoblastoma genome stability. Genes Chromosomes Cancer 53: 1-14, 2014.

50. Dimaras H, Khetan V, Halliday W, Orlic M, Prigoda NL, Piovesan B, Marrano P, Corson TW, Eagle RC Jr, Squire JA and Gallie BL: Loss of RB1 induces non-proliferative retinoma: Increasing genomic instability correlates with progression to retinoblastoma. Hum Mol Genet 17: 1363-1372, 2008.
51. Flavahan WA, Gaskell E and Bernstein BE: Epigenetic plasticity and the hallmarks of cancer. Science 357: pii: eaal2380, 2017.

52. Xia L, Huang W, Bellani M, Seidman MM, Wu K, Fan D, Nie Y, Cai Y, Zhang YW, Yu LR, et al: CHD4 Has oncogenic functions in initiating and maintaining epigenetic suppression of multiple tumor suppressor genes. Cancer Cell 31: 653-668 e7, 2017.

53. Smith ZD and Meissner A: DNA methylation: Roles in mammalian development. Nat Rev Genet 14: 204-220, 2013.

54. Akdeniz D, Tuncer SB, Kebudi R, Celik B, Kuru G, Kilic S, Sukruoglu Erdogan O, Avsar M, Buyukkapu Bay S, Tuncer S and Yazici $\mathrm{H}$ : Investigation of new candidate genes in retinoblastoma using the TruSight One 'clinical exome' gene panel. Mol Genet Genomic Med 7: e785, 2019.

This work is licensed under a Creative Commons Attribution-NonCommercial-NoDerivatives 4.0 International (CC BY-NC-ND 4.0) License. 